\section{HUMAN CYTOKINE RESPONSES TO CARDIAC TRANSPLANTATION AND CORONARY ARTERY BYPASS GRAFTING}

Cardiac surgery with cardiopulmonary bypass triggers an inflammatory response involving proinflammatory cytokines such as tumor necrosis factor- $\alpha$, interleukin-6, and interleukin-8. To elucidate the pathophysiology of this cytokine response, we explored the possible differences in cytokine responses between patients undergoing heart transplantation and those undergoing coronary artery bypass grafting. Plasma levels of tumor necrosis factor- $\alpha$, interleukin-6, interleukin-8, and interleukin-10 were measured in eight patients undergoing heart transplantation (mean age 44 years) and eight patients undergoing coronary artery bypass grafting (mean age 61 years). Duration of cardiopulmonary bypass and ischemic time were both longer in the heart transplantation group than in the coronary artery bypass grafting group $(133 \pm 26 \mathrm{~min}$ vs $100 \pm 31 \mathrm{~min}, p<$ 0.05 , and $130 \pm 47 \mathrm{~min}$ vs $58 \pm 21 \mathrm{~min}, p<0.005$, respectively). Samples were collected before heparin administration, at aortic crossclamping and declamping, and at $0.5,1,1.5,2,4,12$, and 24 hours after declamping. Tumor necrosis factor- $\alpha$ levels were significantly higher 30 minutes after aortic declamping in the heart transplantation group than in the coronary artery bypass grafting group $(68 \pm 30$ vs $18 \pm 5 \mathrm{pg} / \mathrm{ml}, p<0.05)$. Interleukin-6 and interleukin-8 levels were also significantly higher 90 minutes after declamping in patients undergoing heart transplantation than in those undergoing coronary artery bypass grafting $(310 \pm 63 \mathrm{vs}$ $169 \pm 24 \mathrm{pg} / \mathrm{ml}, p<0.05$, and $73 \pm 17 \mathrm{vs} 24 \pm 5 \mathrm{pg} / \mathrm{ml}, p<0.01$, respectively). Furthermore, interleukin-6 and interleukin-8 values 90 minutes after declamping were significantly correlated with the ischemic time $(r=0.72$ and $r=0.82$, respectively, both $p<0.05$ ). Interleukin-10 levels in both groups rose to reach a peak value of around $115 \mathrm{pg} / \mathrm{ml} 1$ hour after declamping. Patients undergoing heart transplantation exhibited a second peak of tumor necrosis factor- $\alpha$, interleukin-8, and interleukin- 10 levels 12 hours after declamping, probably related to the administration of rabbit antihuman thymocyte immunoglobulin (Thymoglobuline) 3 hours after declamping. Interleukin-6 levels decreased more significantly 12 and 24 hours after declamping in patients undergoing heart transplantation, probably related to methylprednisolone therapy. In conclusion, cardiopulmonary bypass is associated with the production of both proinflammatory and antiinflammatory cytokines. The production of proinflammatory cytokines in patients undergoing heart transplantation is higher than that in pa-

Song Wan, MD, a Arnaud Marchänt, MD, ${ }^{\mathrm{b}}$ Jean-Marie DeSmet, MD, ${ }^{\mathrm{a}}$ Martine Antoine, MD, ${ }^{a}$ Haibo Zhang, MD, PhD, ${ }^{c}$ Jean-Luc Vachiery, MD, ${ }^{d}$ Michel Goldman, MD, PhD, ${ }^{\mathrm{b}}$ Jean-Louis Vincent, $\mathrm{MD}, \mathrm{PhD},{ }^{\mathrm{c}}$ and Jean-Louis LeClerc, MD, ${ }^{a}$ Brussels, Belgium
From the Departments of Cardiac Surgery, ${ }^{a}$ Immunology, ${ }^{b}$ Intensive Care; ${ }^{c}$ and Cardiology, ${ }^{d}$ University Hospital Erasme, Free University of Brussels, Brussels, Belgium. Supported in part by Fondation pour la Chirurgie Cardiaque ASBL. Dr. Marchant is a research assistant of the Fonds National de la Recherche Scientifique, Belgium.

Received for publication Jan. 16, 1995.

Accepted for publication April 26, 1995.
Address for reprints: Jean-Louis LeClerc, MD, Department of Cardiac Surgery, University Hospital Erasme, Free University of Brussels, Route de Lennik 808, B-1070, Brussels, Belgium.

J THORAC CARdiovasc Surg 1996;111:469-77

Copyright (C) 1996 by Mosby-Year Book, Inc.

$0022-5223 / 96 \$ 5.00+0 \quad \mathbf{1 2} / \mathbf{1} / \mathbf{6 5 8 9 2}$ 
tients undergoing coronary artery bypass grafting, and this increase could be related to the longer duration of ischemia in the former group. The later course of cytokine levels after heart transplantation may be further influenced by immunosuppressive therapy. (J ThORAC CARDIOvasC SURG 1996; 111:469-77)

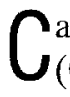
ardiac surgery with cardiopulmonary bypass (CPB) is associated with a systemic inflammatory response that can lead to postoperative multiorgan dysfunction. ${ }^{1,2}$ These deleterious effects of CPB may be caused by the exposure of blood to the extracorporeal circuit and by postischemic reperfusion of the heart and lungs, resulting in complement activation and release of oxygen free radicals and other mediators. ${ }^{1-6}$ Attention has been focused recently on the roles of cytokines such as interleukin- 6 (IL-6) and interleukin-8 (IL-8) in the inflammatory injury seen after CPB. ${ }^{7-13}$ The release of tumor necrosis factor- $\alpha$ (TNF- $\alpha$ ) has also been reported, although less consistently. $7,9,12,14-17$

Clinical investigations to date have included only those patients undergoing elective coronary artery bypass grafting $(\mathrm{CABG})$, valvular surgery, or correction of congenital defects, but the cytokine response after heart transplantation (HTx) may also be of interest. The early phase of HTx presents some important differences from $\mathrm{CABG}$, including longer duration of acute ischemia starting from aortic crossclamping on the donor heart, so a stronger cytokine response might be expected to be elicited.

Interleukin-10 (IL-10) has recently been reported as an antiinflammatory cytokine that deactivates both monocytes and macrophages and is therefore likely to reduce the release of TNF- $\alpha$, IL- 6 , and IL-8. ${ }^{18,19}$ IL-10 is also produced during human sepsis $^{20}$ and could be involved in controlling the post-CPB inflammatory response.

We performed a prospective descriptive pilot study to examine the plasma levels of TNF- $\alpha$, IL- 6 , IL-8, and IL-10 during and after HTx and CABG.

\section{Patients and methods}

The study was approved by the local ethics committee, and informed verbal consent was obtained from each patient. Eight consecutive patients undergoing HTx and eight consecutive patients undergoing elective $\mathrm{CABG}$ for ischemic heart disease were studied. Clinical characteristics of both groups of patients are shown in Table I. All patients received a similar balanced anesthetic regimen, including sufentanil and midazolam. Curarization was achieved with pancuronium. Cefamandol (Mandol) was given intravenously for antimicrobial prophylaxis at a
Table I. Clinical characteristics

\begin{tabular}{lcc}
\hline & $\begin{array}{c}\text { HTx group } \\
(n=8)\end{array}$ & $\begin{array}{c}\text { CABG group } \\
(n=8)\end{array}$ \\
\hline $\begin{array}{l}\text { Sex ratio (male/female) } \\
\text { Age (yr) }\end{array}$ & $7: 1$ & $6: 2$ \\
$\quad$ Mean $\pm \mathrm{SD}^{*}$ & $44 \pm 18$ & $61 \pm 9$ \\
$\quad$ Range & $7-65$ & $47-73$ \\
Body surface area & $1.76 \pm 0.39$ & $1.87 \pm 0.23$ \\
$\quad$ (m ${ }^{2}$ mean $\left.\pm \mathrm{SD}\right)$ & & \\
Diagnosis & $\mathrm{DC}=6, \mathrm{IC}=2$ & $\mathrm{IHD}$ \\
CPB time (min) & $133 \pm 26$ & $100 \pm 31$ \\
$\quad$ Mean $\pm \mathrm{SD} *$ & $91-166$ & $37-130$ \\
$\quad$ Range & & \\
Crossclamp time (min) & & $58 \pm 21$ \\
$\quad$ Mean $\pm \mathrm{SD}$ & $58-101$ & $22-82$ \\
Range & & \\
Ischemic time (min) & $130 \pm 47$ & $58 \pm 21$ \\
$\quad$ Mean $\pm \mathrm{SD} \dagger$ & $55-199$ & $22-82$ \\
$\quad$ Range &
\end{tabular}

$D C$, Dilated cardiomyopathy; $I C$, ischemic cardiomyopathy; $I H D$, ischemic heart disease.

$* p<0.05$ between groups.

$t p<0.005$ between groups.

dosage of $2 \mathrm{gm}$ at induction of anesthesia followed by 2 gm every 6 hours for 48 hours. All patients received aprotinin (Trasylol) at a dosage of $280 \mathrm{mg}$ intravenously within 30 minutes of the beginning of the operation, 280 $\mathrm{mg}$ infused by pump at the start of $\mathrm{CPB}$, and $70 \mathrm{mg}$ /hour intravenously during $\mathrm{CPB}$. Patients undergoing $\mathrm{CABG}$ received no corticosteroids before or during the operation. Those undergoing HTx received azathioprine (Imuran) at a dosage of 3 to $4 \mathrm{mg} / \mathrm{kg}$ after induction of anesthesia and rabbit antihuman thymocyte immunoglobulin (Thymoglobuline) at a dosage of $1 \mathrm{mg} / \mathrm{kg}$ intravenously about 3 hours after aortic declamping, as well as methylprednisolone (Solu-Medrol) 90 minutes after declamping (500 mg intravenously) and every 8 hours thereafter $(125 \mathrm{mg})$ during the first postoperative day. Recipient selection for HTx, donor criteria, and organ procurement have been described elsewhere. ${ }^{21}$ All patients in the HTx group underwent orthotopic cardiac transplantation by the standard Lower and Shumway technique. ${ }^{22}$

The extracorporeal circuit, consisting of a roller pump (Stockert Instrumente GmbH, Munich, Germany) and a membrane oxygenator (Univox-IC, Baxter Healthcare Corp., Bentley Division, Irvine, Calif.) was uniformly employed. Pump flow was kept at 2.0 to $2.5 \mathrm{~L} / \mathrm{min} / \mathrm{m}^{2}$. Heparin (loading dose of $3 \mathrm{mg} / \mathrm{kg}$ ) was infused to maintain an activated clotting time of more than 480 seconds during CPB. Cold crystalloid cardioplegia containing a 


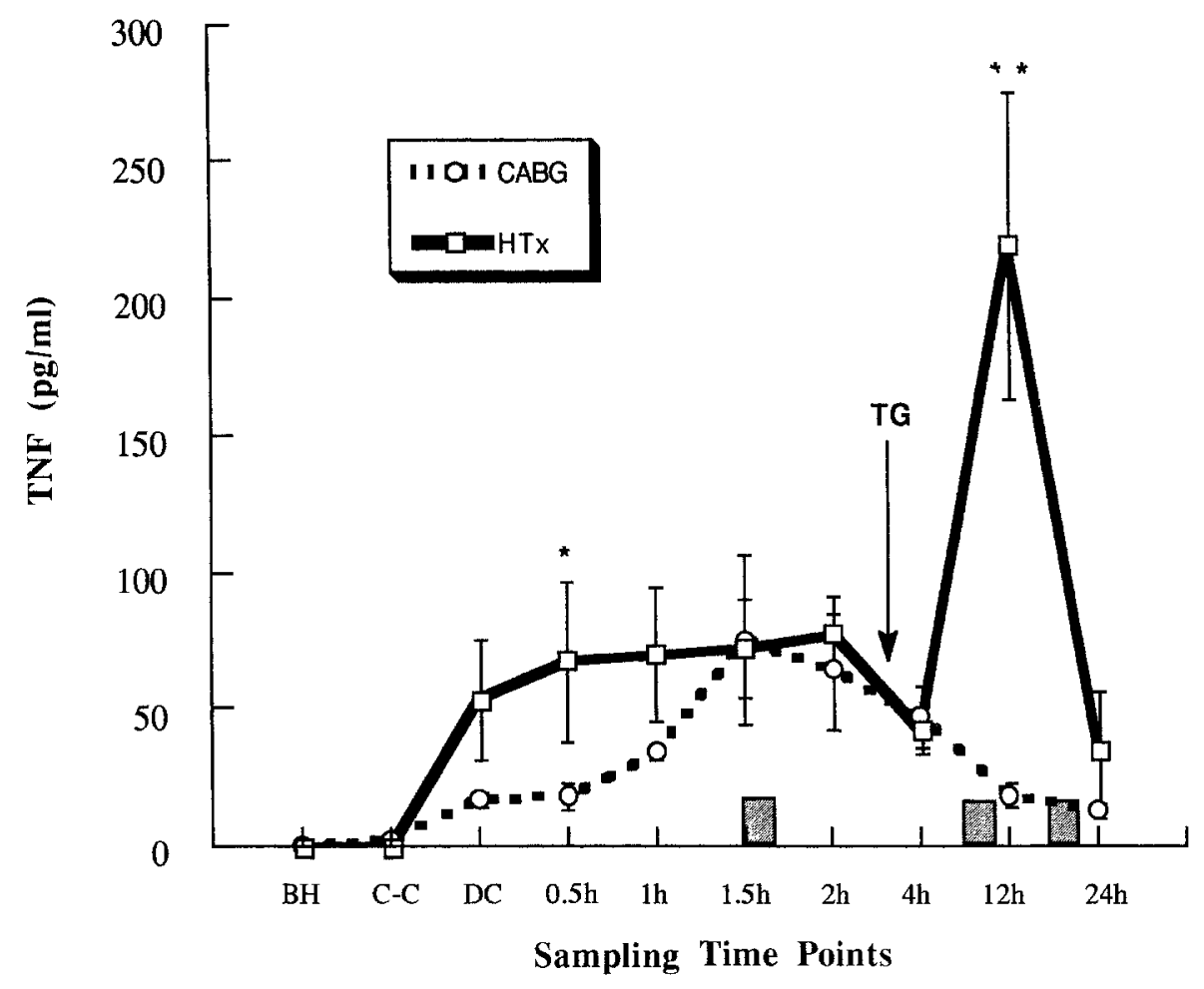

Fig. 1. Plasma TNF- $\alpha$ levels in patients undergoing $\operatorname{HTx}(n=8)$ or CABG $(n=8)$. Asterisk indicates $p<$ 0.05 vs CABG group; double asterisk indicates $p<0.002$ vs CABG group. Data are mean \pm SEM. $B H$, Before heparin administration; $C-C$, crossclamping; $D C$, declamping; $T G$, rabbit antihuman thymocyte immunoglobulin. Shaded bars indicate steroid administration in HTx group.

Ringer's lactate solution with potassium and magnesium chloride as well as sodium bicarbonate, supplemented by slush topical hypothermia, was used for cardiac preservation in all cases. After each distal anastomosis in the CABG group, 80 to $120 \mathrm{ml}$ additional cold cardioplegia was delivered through the vein graft. Patients in the HTx group were cooled to between $26^{\circ}$ and $28^{\circ} \mathrm{C}$ and patients in the $\mathrm{CABG}$ group were cooled to $30^{\circ} \mathrm{C}$. Rewarming began during the aortic anastomosis in the HTx group and during the final distal anastomosis in the CABG group. The proximal anastomoses were completed in the latter group with the aid of a tangential clamp after removal of the crossclamp. On discontinuation of $\mathrm{CPB}$, heparin was neutralized with protamine sulfate in a $2: 3$ ratio with respect to total dosage of heparin. Inotropic support consisting of a dobutamine infusion was provided at the end of operation in all patients in the HTx group and in five patients in the CABG group. Temporary pacing was also used in all patients in the HTx group and in two patients in the CABG group.

Blood was collected from peripheral arterial lines or the arterial side of the pump circuit on an event-based schedule as follows: (1) just before heparin administration, (2) immediately after aortic crossclamping, (3) immediately after aortic declamping, and at (4) 30 minutes, (5) 60 minutes, (6) 90 minutes, (7) 2 hours, (8) 4 hours, (9) 12 hours, and (10) 24 hours after aortic declamping. All samples were anticoagulated with ethylenediaminetetraacetic acid, immediately cooled to $4^{\circ} \mathrm{C}$, and centrifuged within 30 minutes ( $3000 \mathrm{~g}$ for 10 minutes at $4^{\circ} \mathrm{C}$ ). Plasma was stored at $-20^{\circ} \mathrm{C}$ until assay.

TNF- $\alpha$, IL- 6, IL- 8 , and IL-10 plasma levels were determined by means of commercially available enzyme-linked immunosorbent assays (Medgenix Diagnostics SA, Fleurus, Belgium). No adjustment was made for hemodilution. The sensitivities were $15 \mathrm{pg} / \mathrm{ml}$ for TNF- $\alpha, 30 \mathrm{pg} / \mathrm{ml}$ for IL-6, $7 \mathrm{pg} / \mathrm{ml}$ for IL-8, and $11 \mathrm{pg} / \mathrm{ml}$ for IL-10.

Data are expressed as mean \pm standard error of the mean (SEM) unless otherwise indicated. At each time point, the Mann-Whitney $U$ test was used for statistical comparison of cytokine levels between HTx and CABG groups. The Spearman correlation coefficient test was used to explore the correlation between cytokine levels and ischemic time. A $p$ value $<0.05$ was considered to be significant.

\section{Results}

Patients. Table I summarizes clinical characteristics of the patients studied. All patients survived the hospital stay. All patients in the CABG group but one, who received only two venous grafts, received three to four bypass grafts, including one internal mammary artery grafted onto the left anterior de- 


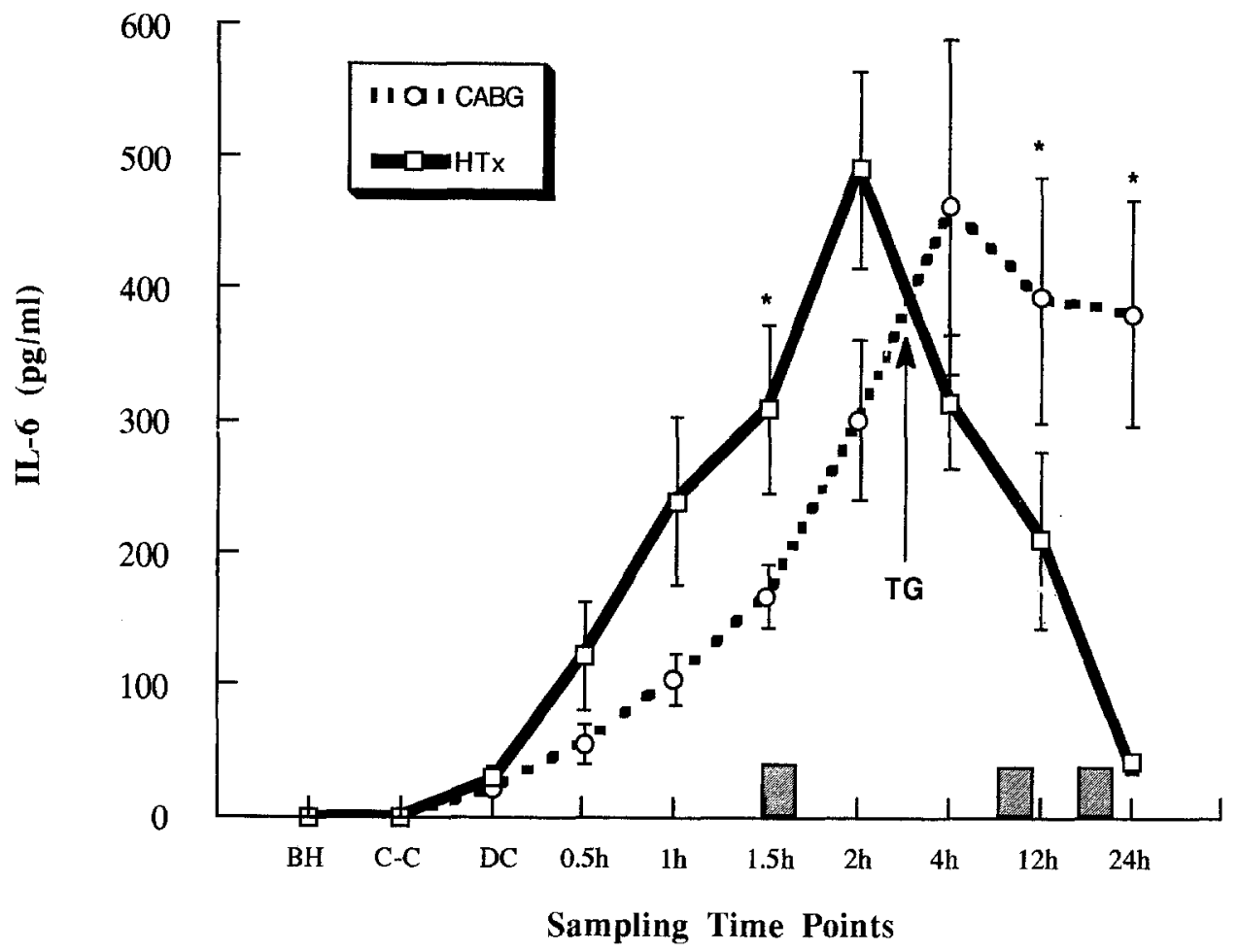

Fig. 2. Plasma IL-6 levels in patients during and after $\operatorname{HTx}(n=8)$ and CABG $(n=8)$. Asterisk indicates $p<0.05$ vs CABG group. Data are mean \pm SEM. $B H$, Before heparin administration; $C$ - $C$, crossclamping; $D C$, declamping; $T G$, rabbit antihuman thymocyte immunoglobulin. Shaded bars indicate steroid administration in HTx group.

scending coronary artery. As expected, duration of $\mathrm{CPB}$ and ischemic time (starting from aortic crossclamping on the donor heart in the HTx group) was longer in the HTx group than in the CABG group (Table I). No patient required reexploration for bleeding after operation.

Cytokines. TNF- $\alpha$ (Fig. 1). TNF- $\alpha$ levels increased immediately after aortic declamping in both groups and reached their peak value 1.5 to 2 hours after reperfusion. TNF- $\alpha$ levels 30 minutes after declamping were significantly higher in the HTx group than in the $\mathrm{CABG}$ group. In the HTx group there was a second peak of TNF- $\alpha$ levels 12 hours after declamping, after administration of rabbit antihuman thymocyte immunoglobulin.

IL-6 (Fig. 2). In both groups of patients, IL-6 levels increased after aortic declamping. IL-6 levels rose higher in the HTx group but decreased earlier in these patients. IL- 6 levels 90 minutes after declamping were significantly correlated with ischemic time (Fig. 3).

IL-8 (Fig. 4). The IL-8 levels increased in both groups after aortic declamping, but more so in the
HTx group than in the CABG group. IL- 8 levels 90 minutes after declamping were significantly correlated with ischemic time (Fig. 3). Patients in the HTx group also showed a second peak in IL-8 levels 12 hours after reperfusion.

IL-10 (Fig. 5). Plasma IL-10 levels increased in both groups during the 2 hours after aortic declamping. The degree of increase in IL-10 levels was similar in the two groups of patients. Interestingly, there was also a second peak release of IL-10 in the HTx group 12 hours after declamping, probably influenced by immunosuppressive therapy.

\section{Discussion}

This study documented the release of proinflammatory cytokines, including TNF- $\alpha$, IL-6, and IL-8, in patients undergoing $\mathrm{HTx}$ and CABG. It also showed the release of IL-10 under these conditions.

The release of cytokines during CPB has been documented recently by several groups of investigators. $^{7-17}$ TNF- $\alpha$ is a potent proinflammatory cytokine susceptible to induce hypotension and organ damage. TNF- $\alpha$ levels were not detectable in many 

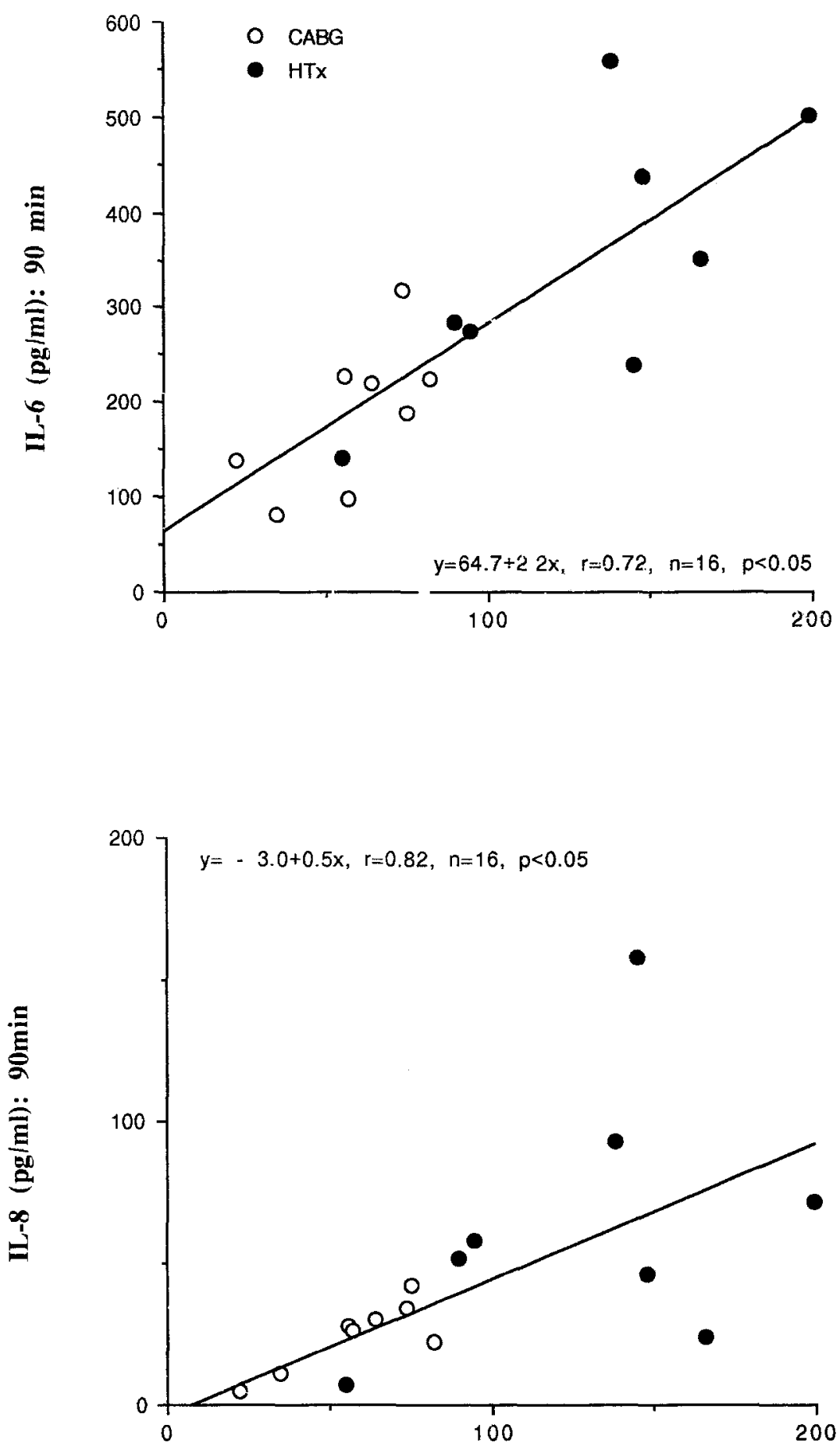

Ischemic Time (min)

Fig. 3. Correlation between plasma IL-6 and IL-8 levels 90 minutes after aortic declamping and ischemic times in the 16 patients. 


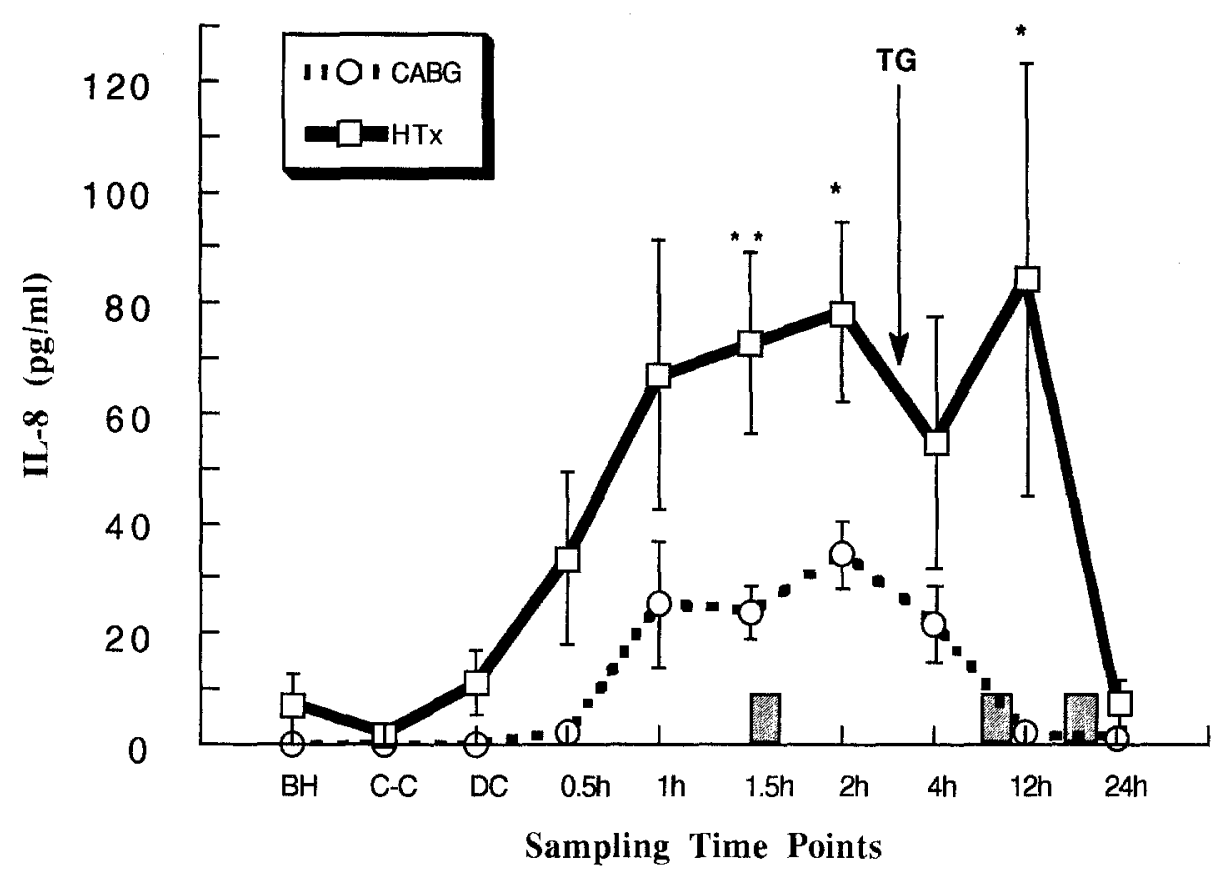

Fig. 4. Plasma IL-8 levels in the HTx $(n=8)$ and CABG $(n=8)$ groups. Asterisk indicates $p<0.05$ vs CABG group; double asterisk indicates $p<0.01$ vs CABG group. Data are mean \pm SEM. BH, Before heparin administration; $C$ - $C$, crossclamping; $D C$, declamping; $T G$, thymocyte immunoglobulin. Shaded bars indicate steroid administration in HTx group.

previous studies, $7,9,12,15-17$ but were measured in a few. ${ }^{14,23,24}$ These differences may be caused in part by the different kits or different methods of measurement used. We found TNF- $\alpha$ levels to be detectable in both groups of patients after declamping, but this increase was quite modest. Patients in the HTx group had a somewhat greater release of TNF- $\alpha$, but the difference was significant only at 30 minutes after declamping. IL-6 does not have major hemodynamic effects but does play an important role in the acute-phase response, primarily concerning the liver. It has been suggested that IL-6 may be a marker whose levels are directly related to the risk of postoperative complications. ${ }^{13}$ Several investigators reported that IL-6 levels already increased after protamine administration, ${ }^{7}$ at the end of operation, ${ }^{8}$ and in the first hour after declamping. ${ }^{12}$ IL- 8 does not have significant hemodynamic effects, but it plays an important role in leukocyte activation. ${ }^{12}$ It has also been suggested that IL-8 may exert protective effects by preserving endothelial function, reducing neutrophil infiltration of the necrotic myocardium, and reducing myocardial necrosis; it would thus provide a significant degree of endothelial and myocardial protection against reperfusion injury. ${ }^{25}$
It is now recognized, however, that IL-8 plays a critical role in multiorgan failure after $\mathrm{CPB},{ }^{13}$ as it does in septicemia, ${ }^{26}$ and may also contribute to myocyte reperfusion injury during human $\mathrm{HTx}^{27}$ Our data confirm previous investigations reporting the release of IL- 8 during and after $\mathrm{CPB}^{9-12,17}$ or after reperfusion. ${ }^{23,24,27}$

In addition, our data also provide some important information regarding the mechanisms involved in the release of these proinflammatory cytokines. This is so for two reasons. First, the comparison of the cytokine release in patients after HTx and after CABG revealed that IL- 6 and IL- 8 levels, as well as TNF- $\alpha$ levels, were significantly higher after declamping in the HTx group. Moreover, IL-6 and IL-8 levels 90 minutes after declamping significantly correlated with ischemic time, suggesting that the degree of IL-6 and IL-8 expression is strongly related to the degree of ischemia. Recently, Hennein and associates ${ }^{23}$ also noted that aortic crossclamp time was an independent predictor of postoperative TNF- $\alpha$, IL- 6 , and possibly IL- 8 levels. Differences in temperature may also be important. ${ }^{9}$ On the one hand, Menasché and colleagues ${ }^{24}$ reported that TNF- $\alpha$ and IL- 6 levels were higher 2 


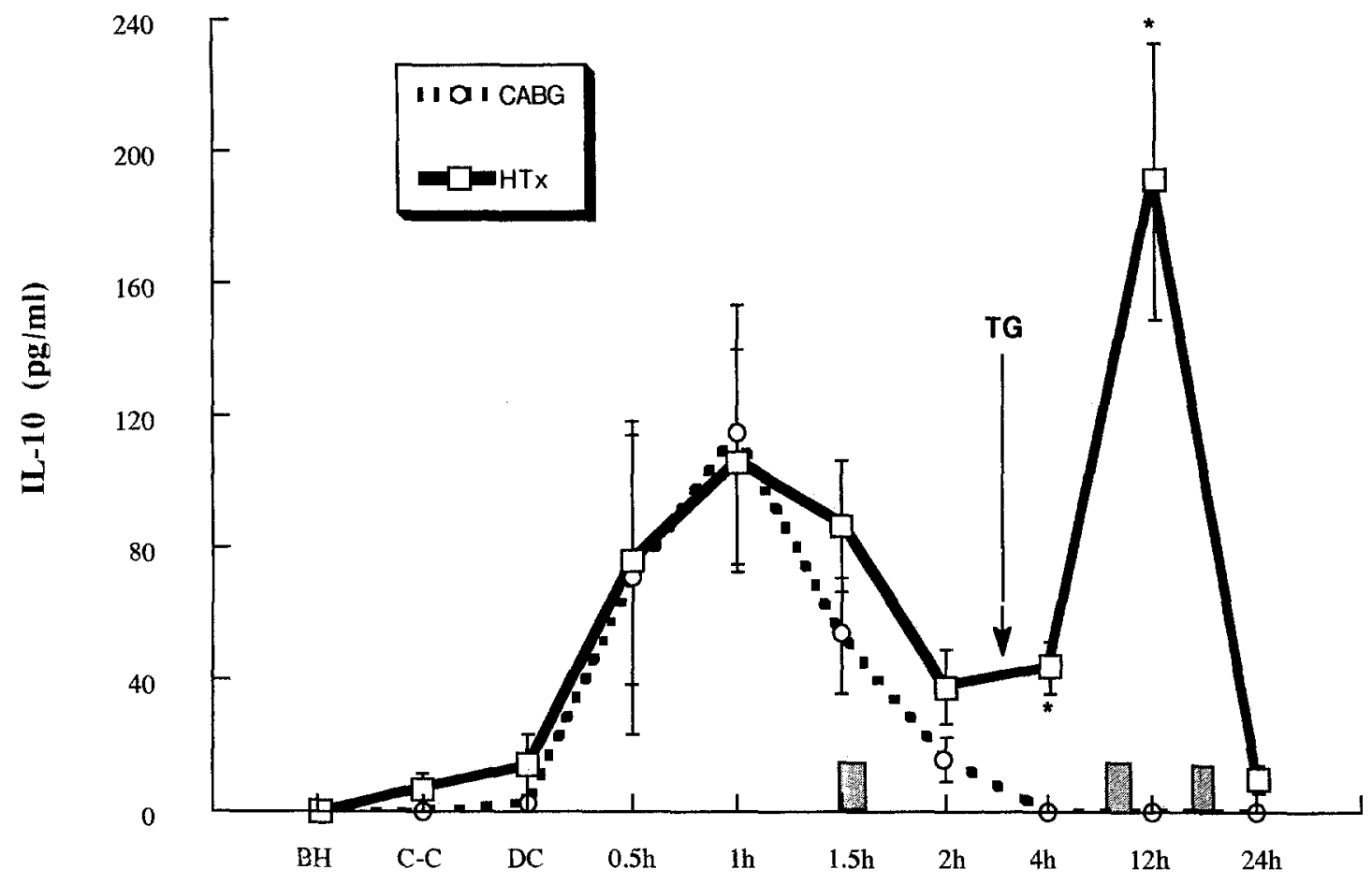

Sampling Time Points

Fig. 5. Plasma IL-10 levels in patients undergoing HTx $(n=8)$ and CABG $(n=8)$. Asterisk indicates $p<$ 0.05 vs $\mathrm{CABG}$ group. Data are mean \pm SEM. $B H$, Before heparin administration; $C$ - $C$, crossclamping; $D C$, declamping; $T G$, thymocyte immunoglobulin. Shaded bars indicate steroid administration in HTx group.

hours after $\mathrm{CPB}$ after normothermic $\left(37^{\circ} \mathrm{C}\right)$ than after hypothermic $\left(28^{\circ}\right.$ to $\left.30^{\circ} \mathrm{C}\right)$ heart operations, indicating that cytokine release may be temperature dependent. On the other hand, Frering and associates $^{17}$ found that changes in temperature did not induce the production of IL-6 and IL-8. In our study, however, the differences in cytokine levels between the HTx group and the CABG group could hardly be explained by the minor difference in temperature at the end of the two procedures. As expected, patients in the HTx group were also younger than those in the CABG group, but there is no good evidence that the cytokines release are significantly influenced by age. Aprotinin may have antiinflammatory effects, but it was given to all patients and thus does not account for the differences between groups.

Second, our sampling times were somewhat different than in those used in previous studies because we selected time points by aortic declamping only, regardless of the duration of CPB. We observed that the cytokine release during ischemia was insignificant but became striking after aortic declamping. As suggested by some experiments, ${ }^{28}$ it appears that reperfusion of the heart and lungs at the time of declamping could represent a major cause of proinflammatory cytokine release in patients undergoing CPB. TNF- $\alpha$, IL- 6 , and IL- 8 were hardly released at the end of ischemic period, even when it was long, but were released later, which strongly suggests that reperfusion is an important trigger of this cytokine response.

Another interesting aspect of our study was the observation during CPB of a significant release of IL-10, which is considered an antiinflammatory cytokine capable of inhibiting some proinflammatory cytokines, including TNF- $\alpha$, IL-6, and IL-8. ${ }^{18-20}$ Interestingly, in contrast to production of proinflammatory cytokines, IL-10 production was unrelated to the duration of ischemia. It is noteworthy that cytokines are likely to act both individually and within a network of interrelated and interacting signals and may be much more detrimental in 
combination..$^{13,28,29}$ For instance, TNF- $\alpha$ and IL-1 can exert their effects directly as well as through the expression of IL-6, and even IL-8, by many cell types. ${ }^{29,30}$ Furthermore, it has been suggested recently that TNF- $\alpha$ is involved both in vitro ${ }^{31}$ and in vivo $^{32}$ in the induction of IL-10, a cycle that provides a negative feedback to TNF- $\alpha$ production.

In the HTx group, cytokine response also appeared to be influenced by immunosuppressive therapy. Obviously, a control HTx group without immunosuppressive therapy could not be considered, so the effects of immunotherapy can be evaluated only by comparison with the CABG group. In the HTx group, TNF- $\alpha$ levels dramatically increased 12 hours after $\mathrm{CPB}$, probably under the influence of the rabbit antihuman thymocyte immunoglobulin administration and despite the earlier administration of steroids known to inhibit the release of TNF- $\alpha .{ }^{14}$ IL-6 levels decreased more rapidly than after $\mathrm{CABG}$, probably under the influence of steroids. ${ }^{33}$ IL-8 levels also presented a second peak, probably also related to the administration of rabbit antihuman thymocyte immunoglobulin and perhaps mediated by TNF- $\alpha$. As observed for TNF- $\alpha$ and IL-8, IL-10 levels showed a second peak in the HTx group; this was probably also induced by immunosuppressive therapy. IL-10 may be involved in the immunosuppression of transplant recipients, as supported by the observation that cyclosporine $\mathrm{A}$ can dramatically enhance endotoxin-induced IL-10 production. ${ }^{34}$

In conclusion, the elevation of the levels of proinflammatory cytokines TNF- $\alpha$, IL- 6 , IL- 8 are shown to be more pronounced in patients undergoing $\mathrm{HTx}$ than those undergoing $\mathrm{CABG}$, and these differences are related at least in part to a longer duration of ischemia in the HTx group. Our study also indicates that antiinflammatory cytokine IL- 10 is released during and after $\mathrm{CPB}$, and that the degree of release of IL-10 is not related to the duration of ischemia. In the HTx group, the cytokine responses may also have been influenced by immunosuppressive therapy. Whether anticytokine strategies aiming at a reduction in reperfusion injury can reduce complications after $\mathrm{CPB}$ is an intriguing question that remains open.

We are grateful to the cardiac anesthesiologists and perfusionists in our institution for their assistance and especially to Dr. Luc Barvais for his helpful comments. We also thank Dr. Donat De Groote (Medgenix) for IL-10 determination.

\section{REFERENCES}

1. Kirklin JK, Westaby S, Blackstone EH, Kirklin JW, Chenoweth DE, Pacifico AD. Complement and the damaging effects of cardiopulmonary bypass. J THORAC CaRdiovasc SuRg 1983;86:845-57.

2. Butler J, Rocker GM, Westaby S. Inflammatory response to cardiopulmonary bypass. Ann Thorac Surg 1993;55:552-9.

3. Knudsen F, Andersen LW. Immunological aspects of cardiopulmonary bypass. J Cardiothorac Anesth 1990; 4:245-58.

4. Kloner RA. Does reperfusion injury exist in humans? J Am Coll Cardiol 1993;21:537-45.

5. Davies SW, Duffy JP, Wickens DG, et al. Time-course of free radical activity during coronary artery operations with cardiopulmonary bypass. J THORAC CARDIOVASC SuRG 1993;105:979-87.

6. Lazzarino G, Raatikainen P, Nuutinen $M$, et al. Myocardial release of malondialdehyde and purine compounds during coronary bypass surgery. Circulation 1994;90:291-7.

7. Steinberg JB, Kapelanski DP, Olson JD, Weiler JM. Cytokine and complement levels in patients undergoing cardiopulmonary bypass. $\mathrm{J}$ THORAC CARDIOVASC SURG 1993;106:1008-16.

8. Butler J, Chong GL, Baigrie RJ, Pillai R, Westaby S, Rocker GM. Cytokine responses to cardiopulmonary bypass with membrane and bubble oxygenation. Ann Thorac Surg 1992;53:833-8.

9. Finn A, Naik S, Klein N, Levinsky RJ, Strobel S, Elliott M. Interleukin-8 release and neutrophil degranulation after pediatric cardiopulmonary bypass. $\mathrm{J}$ Thorac Cardiovasc Surg 1993;105:234-41.

10. Kalfin RE, Engelman RM, Rousou JA, et al. Induction of interleukin-8 expression during cardiopulmonary bypass. Circulation 1993;88(5 Pt 2):II401-6.

11. Jorens $P G$, de Jongh $R$, de Backer $W$, et al. Interleukin- 8 production in patients undergoing cardiopulmonary bypass: the influence of pretreatment with methylprednisolone. Am Rev Respir Dis 1993;148:890-5.

12. Kawamura T, Wakusawa R, Okada K, Inada S. Elevation of cytokines during open heart surgery with cardiopulmonary bypass: participation of interleukin 8 and 6 in reperfusion injury. Can J Anaesth 1993;40: 1016-21.

13. Casey LC. Role of cytokines in the pathogenesis of cardiopulmonary-induced multisystem organ failure. Ann Thorac Surg 1993;56(5 Suppl):S92-6.

14. Jänsen NJ, van Oeveren W, van den Broek L, et al. Inhibition by dexamethasone of the reperfusion phenomena in cardiopulmonary bypass. J THORAC CARDIOVASC SURG 1991;102:515-25.

15. Butler J, Pillai R, Rocker GM, Westaby S, Parker D, Shale DJ. Effect of cardiopulmonary bypass on systemic release of neutrophil elastase and tumor necrosis factor. J THorac Cardiovasc Surg 1993;105:2530 . 
16. Haeffner-Cavaillon N, Roussellier N, Ponzio O, et al. Induction of interleukin-1 production in patients undergoing cardiopulmonary bypass. J THORAC CARDIOVASC SURG 1989;98:1100-6.

17. Frering B, Philip I, Dehoux M, Rolland C, Langlois JM, Desmonts JM. Circulating cytokines in patients undergoing normothermic cardiopulmonary bypass. J Thorac Cardiovasc Surg 1994;108:636-41.

18. de Waal Malefyt R, Abrams J, Bennett B, Figdor CG, de Vries JE. Interleukin 10 (IL-10) inhibits cytokine synthesis by human monocytes: an autoregulatory role of IL-10 produced by monocytes. J Exp Med 1991; 174:1209-20.

19. Gérard C, Bruyns C, Marchant A, et al. Interleukin10 reduces the release of tumor necrosis factor and prevents lethality in experimental endotoxemia. J Exp Med 1993;177:547-50.

20. Marchant A, Deviere J, Byl B, De Groote D, Vincent JL, Goldman M. Interleukin-10 production during septicaemia. Lancet 1994;343:707-8.

21. Primo G, LeClerc JL, Antoine M, DeSmet JM, Joris M. A survey of nine years heart transplantation at Erasme Hospital, University of Brussels. Acta Cardiol 1991;46:555-65.

22. Lower RR, Shumway NE. Studies on orthotopic homotransplantation of the canine heart. Surg Forum 1960;11:18-9.

23. Hennein HA, Ebba $\mathbf{H}$, Rodriguez JL, et al. Relationship of the proinflammatory cytokines to myocardial ischemia and dysfunction after uncomplicated coronary revascularization. J THORAC CARDIOvASC SURG 1994;108:626-35.

24. Menasché $\mathrm{P}$, Haydar S, Peynet J, et al. A potential mechanism of vasodilation after warm heart surgery: the temperature-dependent release of cytokines. J Thorac Cardiovasc Surg 1994;107:293-9.

25. Lefer AM, Johnson G, Ma XL, Tsao PS, Thomas GR.
Cardioprotective and endothelial protective effects of (Ala- IL8) ${ }_{77}$ in a rabbit model of myocardial ischaemia and reperfusion. Br J Pharmacol 1991;103: 1153-9.

26. Marty C, Misset B, Tamion F, et al. Circulating interleúkin- 8 concentrations in multiple organ failure of septic and nonseptic origin. Crit Care Med 1994; 22:673-9.

27. $\mathrm{Oz} \mathrm{MC}$, Naka $\mathrm{Y}$, Liao $\mathrm{H}$, et al. Coronary sinus interleukin-8 and myoglobin are elevated following human heart transplantation [Abstract]. Circulation 1994;90(4 Pt 2):I361.

28. Entman ML, Smith CW. Postreperfusion inflammation: a model for reaction to injury in cardiovascular disease. Cardiovasc Res 1994;28:1301-11.

29. Clavien P-A, Harvey PRC, Strasberg SM. Preservation and reperfusion injuries in liver allografts: an overview and synthesis of current studies. Transplantation 1992;53:957-78.

30. Sheron N, Williams R. IL-8 as a circulating cytokine: induction by recombinant tumour necrosis factoralpha. Clin Exp Immunol 1992;89:100-3.

31. Wanidworanun C, Strober W. Predominant role of tumor necrosis factor- $\alpha$ in human monocyte IL-10 synthesis. J Immunol 1993;151:6853-61.

32. van der Poll T, Jansen J, Levi M, ten Cate H, ten Cate JW, van Deventer SJH. Regulation of interleukin 10 release by tumor necrosis factor in humans and chimpanzees. J Exp Med 1994;180:1985-8.

33. Yoshida Y, Iwaki Y, Pham S, et al. Benefits of posttransplantation monitoring of interleukin 6 in lung transplantation. Ann Thorac Surg 1993;55:89-93.

34. Durez P, Abramowicz D, Gérard C, et al. In vivo induction of interleukin 10 by anti-CD3 monoclonal antibody or bacterial lipopolysaccharide: differential modulation by cyclosporin A. J Exp Med 1993;177: $551-5$. 